\title{
Georges Charles Guillain (1876-1961) and Pierre Mollaret (1898-1987) and their legacy to neuroanatomy: the forgotten triangle of Guillain-Mollaret
}

\author{
Ali Çağlar Turgut ${ }^{1} \cdot$ R. Shane Tubbs ${ }^{2,3} \cdot$ Mehmet Turgut $^{4,5}$
}

Received: 5 December 2018 / Accepted: 17 December 2018 / Published online: 4 January 2019

(C) Springer-Verlag GmbH Germany, part of Springer Nature 2019

\section{Introduction}

The eponym "the triangle of Guillain-Mollaret" (GMT), also known as the dentato-rubro-olivary (DRO) pathway or myoclonic triangle (Fig. 1 and cover), remembers two physicians who contributed to defining this polygon in 1931 [1].

French neurologist Georges Charles Guillain (Fig. 1) was born in 1876 in Rouen and began to study medicine in his native town after customary schooling. He received his clinical education at several hospitals in Paris, completed his first scientific study on traumatic lesions of the plexus brachialis, and was awarded his medical doctorate. He worked on nervous diseases during the First World War and in 1923 he gained the professorship of neurology at the Hôpital de la Salpêtrière in Paris. In 1920, Guillain, together with Barré, reported their famous clinical experience defining what is now known as Guillain-Barré syndrome. In 1931, Guillain and Mollaret described the famous anatomical connections encompassing the contralateral dentate nucleus (DN),

R. Shane Tubbs

shanet@seattlesciencefoundation.org

Ali Çağlar Turgut

alicaglar304.at@gmail.com

Mehmet Turgut

drmturgut@yahoo.com

1 Hacettepe University School of Medicine, Ankara, Turkey

2 Seattle Science Foundation, 550 17th Avenue, Suite 600, Seattle, WA 98122, USA

3 Department of Anatomical Sciences, St. George's University, St. George's, Grenada

4 Department of Neurosurgery, Adnan Menderes University School of Medicine, Aydın, Turkey

5 Department of Histology and Embryology, Adnan Menderes University Health Sciences Institute, Aydın, Turkey ipsilateral red nucleus (RN), and ipsilateral inferior olivary nucleus (ION), called the GMT [1]. He was a member of many international medical societies including American and Japanese and he received many scientific honors [5]. In 1947, he retired and, in 1961, died in Paris.

French physician Pierre Mollaret (Fig. 1) was born in 1898 in Auxerre. Together with his teacher Georges Charles Guillain, Mollaret worked for many years on diseases of the nervous system. He received his academic degree in 1926 and completed his thesis for the medical doctorate in 1929; then he worked at the Hôpital de la Salpêtrière. Mollaret was head of the laboratory at the Pasteur Institute from 1935 to 1941 and he worked in the malaria department of the military hospital in Casablanca during the Second World War. Importantly, in 1944, he was the first to report several patients with recurrent aseptic meningitis, known also as Mollaret meningitis [2]. Mollaret made many scientific contributions to neurology

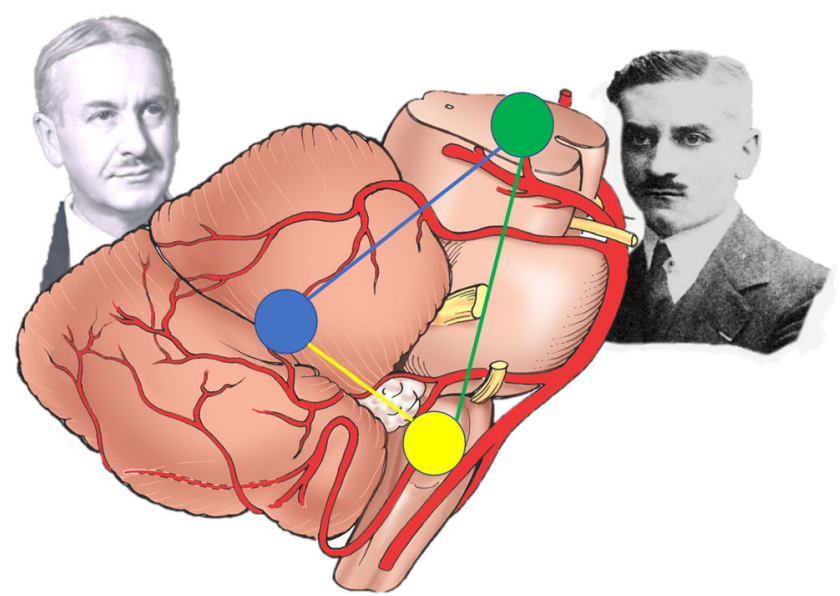

Fig. 1 and cover Drs. Georges Charles Guillain (right) and Pierre Mollaret (left) observing the anatomical triangle of Guillain-Mollaret between the brain stem and the cerebellum - the blue dot represents the dentate nucleus, the green dot the contralateral red nucleus, and the yellow dot the inferior olivary nucleus 
and infectious diseases as an epidemiologist as well as a neurologist. He died in Paris in 1987.

\section{Forgotten triangle of Guillain-Mollaret}

GMT has three vertices: RN within the midbrain, ION in the medulla, and DN in the contralateral cerebellum. It has three interconnecting edges: descending "rubro-olivary fibers" along the central tegmental tractus from the RN to the ipsilateral ION, crossing "olivocerebellar fibers" between the ION and the contralateral cerebellar cortex via the inferior cerebellar peduncle, and "dentatorubral fibers" ascending from the $\mathrm{DN}$ to the contralateral $\mathrm{RN}$ via the contralateral superior cerebellar peduncle to the original RN to complete the DRO by decussating in the midbrain [1, 3] (Fig. 1). However, there is no direct connection between the ION and the contralateral DN [3]. Any injury involving one of the vertices or edges of the triangle results in degeneration, which initially causes hypertrophy of the ION followed by its atrophy, called hypertrophic olivary degeneration, which typically presents with clinical symptoms of cerebellar dysfunction, dysmetria, palatal tremor, or ataxia [4]. Diffusion tensor imaging and fiber tractography can identify disruption of the DRO pathway [4]. Unfortunately, its treatment is palliative.

\section{Compliance with ethical standards}

Conflict of interest The authors have no conflicts of interest.

Publisher's Note Springer Nature remains neutral with regard to jurisdictional claims in published maps and institutional affiliations.

\section{References}

1. Guillain G, Mollaret P (1931) Deux cas de myoclonies synchrones et rythmées vélo-pliaryngo-oculo-diaphragmatiques. Le problème anatomique et physio-pathologique de ce syndrome. Rev Neurol (Paris) 2:545-566

2. Mollaret P (1944) La méningite endothélio-leucocytaire multirécurrente benigne: syndrome nouveau ou maladie nouvelle? Rev Neurol (Paris) 76:57-67

3. Wein S, Yan B, Gaillard F (2015) Hypertrophic olivary degeneration secondary to pontine haemorrhage. J Clin Neurosci 22:1213-1214

4. Goyal M, Versnick E, Tuite P, Cyr JS, Kucharczyk W, Montanera W, Willinsky R, Mikulis D (2000) Hypertrophic olivary degeneration: metaanalysis of the temporal evolution of MR findings. Am J Neuroradiol 21:1073-1077

5. Clarac F, Boller F (2010) Chapter 40: history of neurology in France. Handb Clin Neurol 95:629-656 